\title{
$\underline{\mathbf{P}-77}$
}

\section{Quantification of Rutin, Quercitrin and Quercetin in Cosmos Caudatus Kunth by RP-HPLC}

\author{
Munira Mohd Amin Sharifuldin, Abdalrahim F.A. Aisha and Zhari Ismail ${ }^{*}$ \\ Department of Pharmaceutical Chemistry, School of Pharmaceutical Sciences, Universiti Sains Malaysia, Minden \\ 11800, Pulau Pinang, Malaysia; E-mail: zhari@usm.my
}

Cosmos caudatus is a traditional medicinal plant from the family Compositae. It is known in Malaysia as Ulam Raja which means the king's salad. The fresh leaves are consumed as appetizer for health benefits for various ailments such as to improve blood circulation and to promote the formation of healthy bones. This study aims to develop a reverse phase HPLC method for quantification of rutin, quercitrin and quercetin as the marker compounds in fifteen different $C$. caudatus extracts. The method was validated for selectivity, linearity, precision, accuracy and limits of detection and quantification. Selectivity was confirmed based on retention time and UV-Vis spectra; linearity was in the range $0.5-500 \mu \mathrm{g} / \mathrm{ml}$ at $R^{2}=1.0$; the intraday and interday precision was determined as the relative standard deviation of peak area and retention time, and was found to be $0.3 \pm 0.07 \%$ and $0.02 \pm 0.004 \%$, respectively; percentage recovery of rutin, quercitrin and quercetin was in the range $(91.63 \pm 3.1) \%-$ $(95.93 \pm 3.0) \%,(80.41 \pm 1.5) \%-(93.99 \pm 5.0) \%$, and $(92.84 \pm 3.1) \%-(98.05 \pm 2.6) \%$; the limits of detection were in the range $0.048-$ $0.052 \mu \mathrm{g} / \mathrm{ml}, 0.144-0.157 \mu \mathrm{g} / \mathrm{ml}, 0.078-0.079 \mu \mathrm{g} / \mathrm{ml}$, and the limits of quantification were $0.235-0.236 \mu \mathrm{g} / \mathrm{ml}, 0.152-0.164$ $\mu \mathrm{g} / \mathrm{ml}$, and 0.461-0.497 $\mu \mathrm{g} / \mathrm{ml}$, respectively. Results showed C. caudatus contains high concentration of flavonoids and flavonoid glycosides including rutin, quercitrin, iso-quercitrin and quercetin and quercitrin being the major constituent in this plant. Hence it may be used as a reference compound for standardization of this medicinal herb. In conclusion, the method developed can be used for quantitative analysis in quality control, stability studies, pharmacokinetics, and standardization purpose.

Keywords: Rutin, quercitrin, quercetin, Cosmos caudatus. 